\title{
Development, Characterization and Microbiological Evaluation of Silver Nanoparticles, Obtained by Green Synthesis, from the Extract of Annona muricata L.
}

\author{
Daniele Priscila da Silva Fardin de Assunção ${ }^{1 *}$ \\ https://orcid.org/0000-0002-5112-6709
}

\section{Barbara Justus ${ }^{1}$}

https://orcid.org/0000-0003-3943-9304

\section{Ana Cristina Oltramari Toledo ${ }^{1}$}

https://orcid.org/0000-0002-8477-3734

\section{Josiane de Fátima Padilha de Paula ${ }^{1}$}

https://orcid.org/0000-0002-2717-8867

\author{
${ }^{1}$ State University of Ponta Grossa, Pharmacy Department, Ponta Grossa, Paraná, Brazil. \\ Editor-in-Chief: Paulo Vitor Farago \\ Associate Editor: Paulo Vitor Farago
}

Received: 2020.07.21; Accepted: 2020.11.06.

*Correspondence: danisfardin@hotmail.com; Tel.: +55-42-99800-4633 (D.P.S.F.A.).

\section{HIGHLIGHTS}

- Annona muricata L. extract of pulp, seeds and leaves reduces silver to metallic nanoparticles in a simple green method, with or without light exposition.

- AgNPs synthesized showed the highest antibacterial activity.

\begin{abstract}
Green synthesis is an efficient method, frequently applied in nanobiotechnology, as it does not use toxic reagents or solvents. Biological organisms, including medicinal plants, have been used successfully for manufacturing of different types of metallic nanoparticles. The aim of this work was to synthesize, characterize and evaluate the antimicrobial activity of silver nanoparticles (AgNPs) obtained from the extract of the pulp, seed and leaves of Annona muricata L. The particle size, polydispersity index, zeta potential, as well as morphological aspects of AgNPs were evaluated. With the data obtained from the analyses, we concluded that the nanoparticles were successfully obtained by a simple and green method using the aqueous extract of the pulp, seeds and leaves of $A$. muricata. AgNPs obtained by $A$. muricata pulp extract without exposure to artificial light showed lowest average of hydrodynamic diameter and smallest size at field emission scanning electron microscope (FESEM). In addition, these nanoparticles showed the best polydispersity index (PDI), and zeta potential of - 29.6, which indicates good stability. AgNPs obtained from the extract of the pulp, seed and leaves showed antimicrobial activity, against strains of gram positive and gram negative bacteria, and antifungal activity, compared to the pure extract.
\end{abstract}

Keywords: silver nanoparticles; antimicrobial activity; Annona muricata L. 


\section{INTRODUCTION}

Countless strategies have been developed and used in antimicrobial therapy; most of these strategies improve drug delivery, as in the case of nanocarriers that determine several therapeutic benefits, as the overcoming cases of resistance to multiple drugs [1].

These systems showed a significant decrease in toxicity, instability, and decomposition of drugs. Additionally, they showed the possibility of achieving specific targets, and the possibility of incorporating both hydrophilic and lipophilic substances in the same device, as well the reduction of the therapeutic dose and the frequency of administrations, which complement the main advantages of these systems [2].

Silver nanoparticles (AgNPs) can exert their antibacterial activity by three different mechanisms: (1) the release of $\mathrm{Ag}^{+}$ions, which can bind to thiol groups $(-\mathrm{SH})$, therefore destabilizing the structure of proteins and enzymes of the cell membrane; (2) the adsorption of AgNPs on the bacterial cell membrane that can form pores, leakage of cytoplasmic content, and consequently, cell death; and (3) the production of reactive oxygenated species (ROS), free radicals derived from oxygen that can destabilize the DNA structure and protein denaturation [3].

The green synthesis of metallic nanoparticles using plant extracts has received great attention, as it is a single-step protocol with the availability of large quantities, ecologically correct and low cost that does not involve toxic chemicals [4].

Therefore, AgNPs are of great interest due to their reliability in relation to eco-friendly synthesis and their broad therapeutic properties, such as antimicrobial, antioxidant and anticancer activity [5].

Thus, the green engineering of metallic nanoparticles seems to be a valuable technology for the production of nanoparticles of controlled size and shape, using biological sources, such as plants and microorganisms [6].

Annona muricata $\mathrm{L}$. is a species cultivated in tropical regions of the Americas. It has a new class of phytochemicals, annonaceous acetogenins, which, among other activities, have shown to be antitumor, pesticide, insecticide, antibacterial, antiparasitic, in addition to the immunosuppressive effect. The predominant compounds are acetogenins, followed by alkaloids, phenols, vitamins, and sesquiterpenes [7]. The Annona muricata's action mechanism is probably due to a synergism between these compounds. Some alkaloids have the ability to bind to the DNA of microorganisms and inhibit RNA synthesis [8], and have shown antimicrobial activity by inhibiting glycosidase [9].

Thus, the objective of the present study was to synthesize and characterize metallic silver nanoparticles, using the green synthesis method, and using extracts from the leaves, seeds, and pulp of Annona muricata, in addition to evaluate its antimicrobial activity.

\section{MATERIALS AND METHODS}

\section{Preparation of aqueous extract of $A$. muricata L. pulp, seeds, and leaves}

A. muricata fruit and leaves were obtained from the Municipal Market of Curitiba-Paraná $\left(22^{\circ} 35^{\prime} 58.26 " S\right.$ $\left.47^{\circ} 52^{\prime} 56.47 " \mathrm{O}\right)$.

The extract was prepared using the turboextraction method. $100 \mathrm{~g}$ of pulp was added to $100 \mathrm{~mL}$ of ultrapurified water and homogenized with ultraturrax ${ }^{\circledR}$ IKA at 10,000 RPM. It was then filtered through a Whatmann ${ }^{\circledR}$ filter paper No. 1 and the resultant was stored at $4-8{ }^{\circ} \mathrm{C}$. The seeds of $A$. muricata L. obtained from the fresh fruit were dried in an oven at $37^{\circ} \mathrm{C}$ for 48 hours. After drying, the seeds were macerated in grail ${ }^{\odot}$. The decoction was then carried out using $0.5 \mathrm{~g}$ of dry seed and $50 \mathrm{~mL}$ of ultra-filtered water, at $100 \stackrel{\circ}{\circ}$ for $10 \mathrm{~min}$. It was then filtered through a Whatmann ${ }^{\circledR}$ filter paper No. 1 , and the resultant was stored at $4-8{ }^{\circ} \mathrm{C}$. The extract of the dried leaves was prepared by means of infusion for $30 \mathrm{~min}$, using $2 \mathrm{~g}$ dried leaves with $100 \mathrm{~mL}$ of distilled water. It was then filtered through a Whatmann ${ }^{\circledR}$ filter paper No. 1 and the resultant was stored at $4-8^{\circ} \mathrm{C}$.

\section{Synthesis of AgNPs by A. muricata L.}

Briefly, $1 \mathrm{~mL}$ of pulp extract, leaf extract, or seed extract was added to $9 \mathrm{~mL}$ of an $\mathrm{AgNO}_{3} 1 \mathrm{mM}$ solution. The reduction of the $\mathrm{Ag}^{+}$ions was completed and confirmed by a change in the color, from colorless to dark orange $\left(\mathrm{Ag}^{0}\right)$. The suspension was stored in the dark at $4-8^{\circ} \mathrm{C}$ for further analysis. 


\section{Synthesis of AgNPs by A. muricata L. and by photoreduction}

AgNPs obtained by the aqueous extracts of $A$. muricata L., as previously described, were exposed to artificial light, by the SOLAR ULTRA TROPIC 4000K-LT 24WT5HQ 549NM lamp, made in Germany for JBL ${ }^{\circledR}$, at 5 to 60 minutes. The reduction of $\mathrm{Ag}^{+}$to $\mathrm{Ag}^{0}$ was confirmed by visual evaluation and by UV-vis spectroscopy absorption every 5 minutes.

\section{Characterization of AgNPs}

\section{UV - Visible spectroscopy analysis}

The analyses were carried out using UV-Vis Nir Varian CARY ${ }^{\circledR} 50$ equipment in scan mode, in the 200$800 \mathrm{~nm}$ range with quartz cuvettes. The samples were analyzed in triplicate.

\section{Determination of zeta potential}

The zeta potential of the developed nanoparticles was analyzed using a Zetasizer Nano ZS90 (Malvern ${ }^{\circledR}$ Instruments) apparatus with an angle of incidence of $90^{\circ}$, at a temperature of $25^{\circ} \mathrm{C}$. The suspensions were prepared with Millipore Milli-Q system water in a 1:10 ratio (v:v) and then analyzed in triplicate.

\section{Fourier-transform infrared spectroscopy (FTIR)}

The nanoparticles were analyzed by Fourier-transform infrared spectroscopy to evaluate the functional groups involved in the formation of the nanoparticles. For each sample, a tablet was prepared by cold pressing, which was composed of $\mathrm{KBr}$ at spectroscopic grade $(2 \% \mathrm{w} / \mathrm{w})$ and the powder formed by the nanoparticle to be analyzed. The readings were performed using IR Prestige 21 equipment (Shimadzu ${ }^{\circledR}$ ) with $64 \mathrm{scans} / \mathrm{min}$ and a resolution of $4 \mathrm{~cm}^{-1}$; an experimental window of interest of 4,000 to $400 \mathrm{~cm}-1$ was considered. Pure KBr pellets were used for the baseline reading.

\section{Morphological and surface evaluation}

The morphological analysis of the produced nanoparticles was carried out in a field emission scanning electron microscope (FESEM)(TESCAN ${ }^{\circledR}$, model Mira 3, Brno, Czech Republic). The samples were subjected to gold plating in an IC-50 lon Coater metallizer (SHIMADZU ${ }^{\circledR}$, Kyoto, Japan). To obtain the micrographs, an acceleration voltage of $15 \mathrm{kV}$ and specific software (Electron Optical Design) were used.

\section{Energy dispersive $X$-ray spectroscopy (EDS)}

This technique is used for the elemental analysis or chemical characterization of a sample. Its characterization capabilities are due in large part to the fundamental principle that each element has a unique atomic structure allowing X-rays that are characteristic of an element's atomic structure to be identified uniquely from one another.

\section{Nanoparticle stability tests}

The samples of AgNPs obtained from the extract of the pulp, seed, and leaves of Annona muricata were stored under refrigeration at $4-8^{\circ} \mathrm{C}$, and evaluated in triplicate by UV-vis spectroscopy. After preparation, the samples were analyzed, refrigerated for a period of one year, and analyzed again every 30 days.

\section{Antimicrobial and Antifungal activity}

\section{Broth microdilution method}

The microdilution test was carried out in 96-well plates according to the MCC-A6 protocol of the NCCLS (2004) adapted, using BHI broth (brain heart infusion). Initially, $100 \mu \mathrm{L}$ of the suspension of AgNPs were used, and a serial dilution was performed to obtain final concentrations of $5.4 \mu \mathrm{g} / \mathrm{mL} ; 2.7 \mu \mathrm{g} / \mathrm{mL} ; 1.35 \mu \mathrm{g} /$ $\mathrm{mL} ; 0.675 \mu \mathrm{g} / \mathrm{mL}$, taking into account the silver concentration used in the preparation of the nanoparticles.

Later, $10 \mu \mathrm{L}$ of the microorganism suspension (Staphylococcus aureus, Enterococcus faecalis, Escherichia coli, Pseudomonas aeruginosa, Proteus mirabilis, Enterobacter cloacae, and the Candida 
albicans) were inoculated in each vessel to final concentration near $1 \times 10^{5} \mathrm{CFU} / \mathrm{mL}$. The plates were incubated at $35^{\circ} \mathrm{C}$ for 24 hours. To confirm viable microorganisms in non-inhibitory concentrations, $15 \mu \mathrm{L}$ of the $1 \%$ TCC dye (2,3,5 triphenyltetrazolium chloride) were added and incubated at $35^{\circ} \mathrm{C}$ for 30 minutes.

The minimum bactericidal concentration (MBC) was obtained by sowing the contents of the wells that did not show visible growth. When seeded on to Mueller-Hilton agar plate, the contents were incubated at $37^{\circ} \mathrm{C}$ for 24 hours. The minimum inhibitory concentration (MIC) and MBC for each strain was carried out in triplicate.

\section{RESULTS AND DISCUSSION}

The addition of different parts of the plant, pulp, leaf, and seed extract of Annona muricata L., with or without light exposition, caused a change in the color of the solution from yellowish to reddish brown (Figure 1).
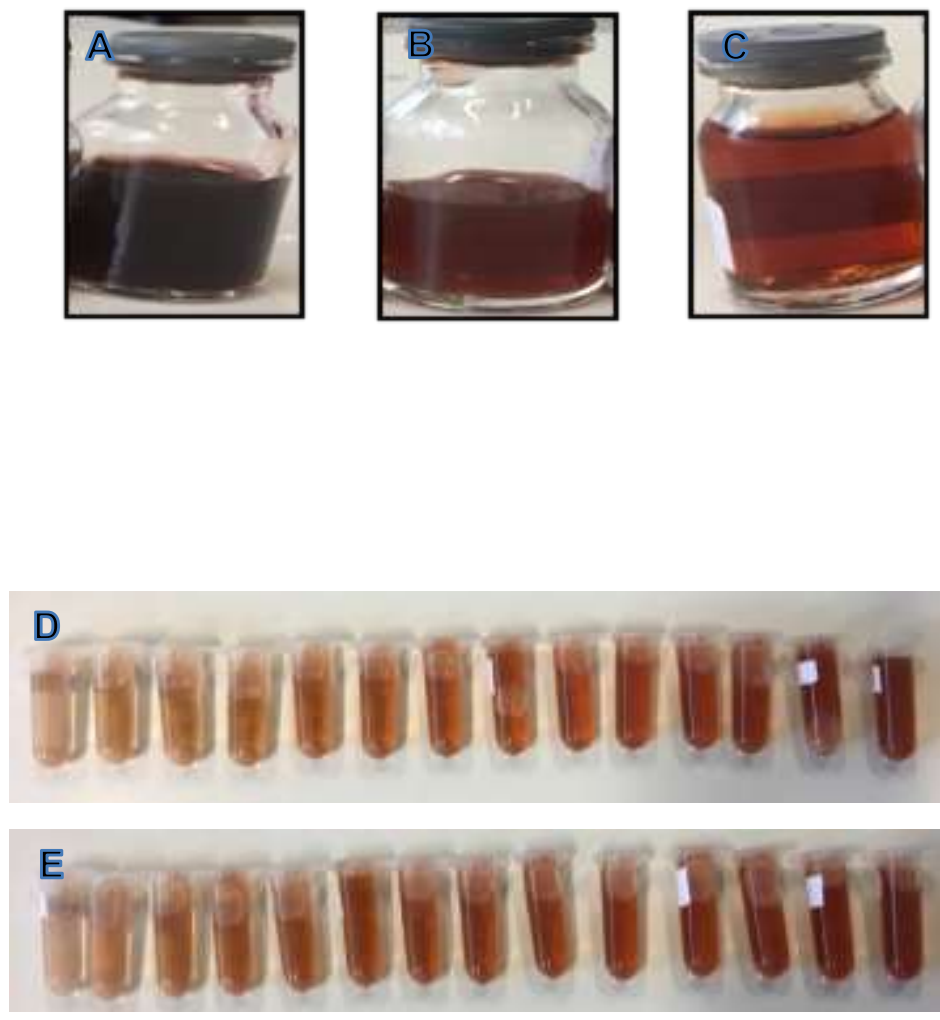

F

Figure 1. Silver nanoparticles using plant extracts without light exposition (A) AgNPs using pulp extract; (B) AgNPs using seeds extract; (C) AgNPs using leaves extract. Silver nanoparticles using plant extracts with light exposition (D) AgNPs using pulp extract; (E) AgNPs using seed extract; (F) AgNPs using leaf extract.

The color change is due the excitation of the surface plasmon resonance (SPR) during the reduction of $\mathrm{AgNO}_{3}{ }^{+}$. These SPR bands undergo a color from red to blue, depending on the size and shape of the nanoparticles [10]. 


\section{UV-Visible spectroscopy analysis}

UV-vis spectra of the AgNPs produced by extract of different parts of the plant: pulp, leaf, and seed, without exposure to artificial light, showed maximum absorption peaks at $444 \mathrm{~nm}, 437 \mathrm{~nm}$ and $424 \mathrm{~nm}$, respectively (Figure 2).

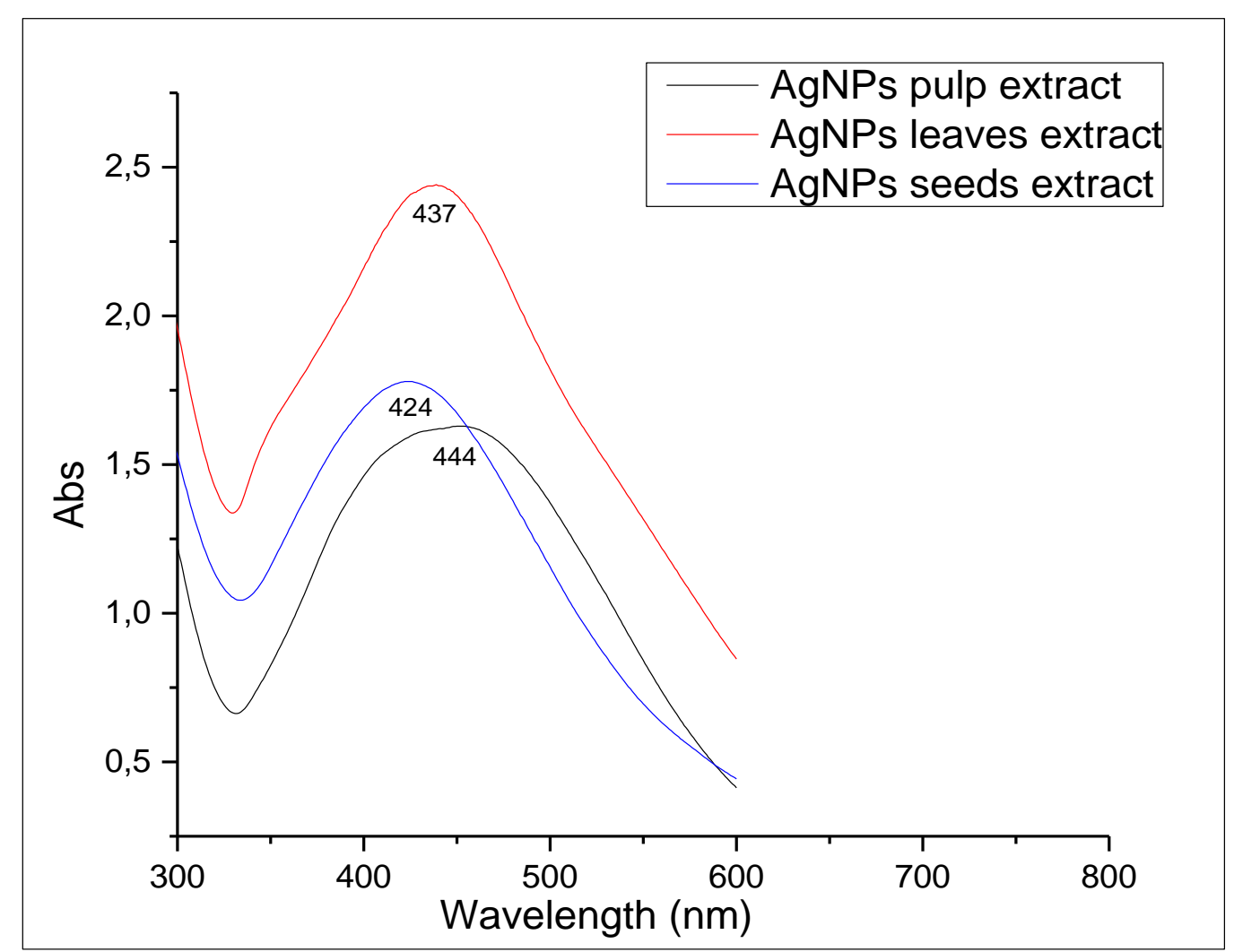

Figure 2. UV-vis spectrum of AgNPs prepared by pulp extract, leaf extract and A. muricata seed extract.

Additionally, UV-vis spectra obtained after exposure to artificial light at a period of 5 to 70 minutes are shown in Figure 3. AgNPs prepared by extract of $A$. muricata pulp (Figure 3A) and seeds (Figure 3B) exposed to artificial light, showed peak at $428 \mathrm{~nm}$ and $442 \mathrm{~nm}$, respectively, after 70 minutes of exposure (Figure 3A). The formation of both AgNPs began at 5 minutes of exposure. Figure $3 \mathrm{C}$ shows the formation of AgNPs obtained by extracting $A$. muricata leaves. The maximum absorption peak occurred at $435 \mathrm{~nm}$ in 70 minutes; however, the onset of the reaction started after 30 minutes, slower than the other extracts, which indicates that leaves contain lower concentrations of reducing agents than the other extracts. 

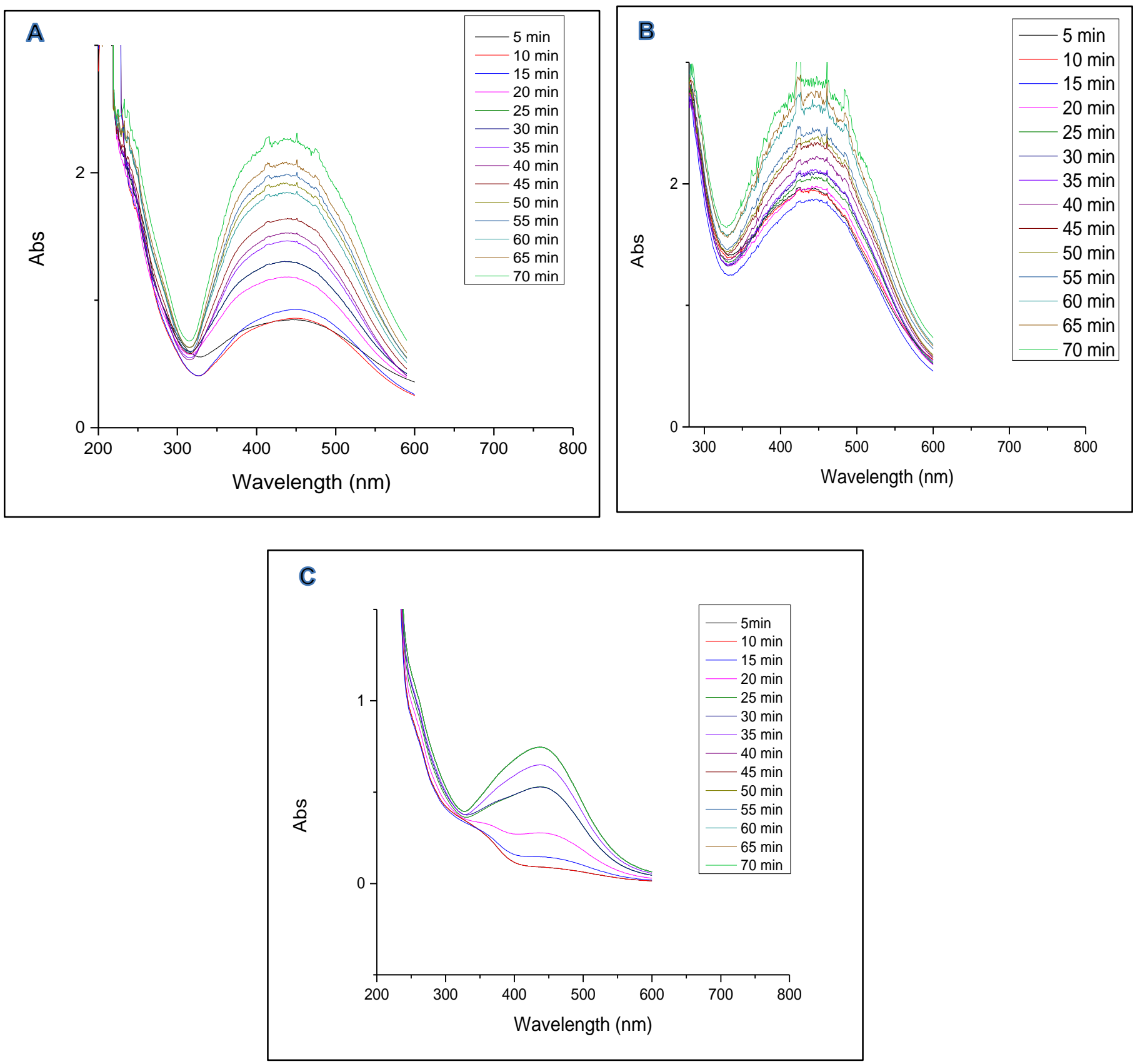

Figure 3. UV-vis spectrum of AgNPs prepared with A. muricata pulp (A), seeds (B) and leaves (C) extract with exposure to artificial light in 5 to 70 minutes.

UV-vis spectroscopy is based on the plasmonic band resonance phenomenon observed in metallic nanoparticles [11]. The surface plasmon resonance for silver occurs between 400 and $500 \mathrm{~nm}$ [12], which is consistent with the results obtained in this work, where the formation of AgNPs were observed between 428 to $442 \mathrm{~nm}$.

The size and shape of AgNPs are the main factors that determine the spectral absorption range where the resonance occurs. Other factors that interfere are electronic density, effective mass and the interaction with their stabilizers and the reaction medium $[13,14]$.

The appearance of the plasmonic peak band at $440 \mathrm{~nm}$ can be suggestive of spherical shape and reduced size [15].

\section{Determination of mean diameter, polydispersity index and zeta potential}

AgNPs obtained by $A$. muricata pulp extract without exposure to artificial light showed lowest average of hydrodynamic diameter and smallest size at field emission scanning electron microscope (FESEM). Moreover, they showed the best polydispersity index (PDI), and zeta potential of - 29.6, which indicates good stability. Table 1 summarizes these results. 
When comparing the size obtained by hydrodynamic diameter average with the measurements of photomicrographs by (FESEM) a difference in the values can be observed, especially in the AgNPs obtained with the leaf extract of $A$. muricata exposed to artificial light and in the AgNPs obtained with $A$. muricata seed extract without exposure to light. It is probably due to the presence of AgNPs clusters that cause a distortion in the values of analysis of hydrodynamic diameter carried out by light scattering (Zetasizer), so these analyses do not express the size of the isolated nanoparticle.

Table 1. Hydrodynamic diameter (Z-average), Zeta potential (ZP), polydispersity index (PDI) and FEG diameter of AgNPs prepared with $A$. muricata pulp, leaves and seeds with and without exposure to artificial light.

\begin{tabular}{llllc} 
& Size $(\mathrm{nm} \pm \mathrm{SD})$ & $\mathrm{ZP}(\mathrm{mV} \pm \mathrm{SD})$ & PDI & FEG $(\mathrm{nm} \pm \mathrm{SD})$ \\
\hline AgNPs Pcl & $87 \pm 10.74$ & $-30.3 \pm 8.5$ & $0.49 \pm 0.17$ & $48 \pm 8.70$ \\
AgNPs Psl & $51.5 \pm 14.56$ & $-29.6 \pm 5.3$ & $0.25 \pm 0.18$ & $31 \pm 0.54$ \\
AgNPs Fcl & $194 \pm 17.32$ & $-33.5 \pm 5.7$ & $0.70 \pm 0.15$ & $46 \pm 4.10$ \\
AgNPs Fsl & $62 \pm 19.25$ & $-27.2 \pm 0.8$ & $0.60 \pm 0.05$ & $60 \pm 2.00$ \\
AgNPs Scl & $60 \pm 18.34$ & $-38.2 \pm 2.5$ & $0.29 \pm 0.24$ & $54 \pm 1.52$ \\
AgNPs Ssl & $205 \pm 28.31$ & $-28 \pm 4.9$ & $0.56 \pm 0.10$ & $47 \pm 1.53$ \\
\hline
\end{tabular}

AgNPs - silver nanoparticles; Pcl- $A$. muricata pulp extract and exposure to light; $\mathrm{Psl}$ - $A$. muricata pulp extract without exposure to light; Fcl - A. muricata leaf extract and exposure to light; Fsl - $A$. muricata leaf extract without exposure to light; Scl - A. muricata seed extract with exposure to light; Ssl - A. muricata seed extract without exposure to light. SD - standard deviation.

Zeta potential of the AgNPs was negative and varied between 27 and $38 \mathrm{mV}$, which indicates that the particles are stable. According to Neves and coauthors [16], zeta potential values around $30 \mathrm{mV}$ present greater stability, while with the values are closer to $5 \mathrm{mV}$, there is a decrease in electrostatic repulsion between the particles and greater aggregation, and consequently, the particles tend to be less stable.

Evaluating the surface load of the AgNPs, it can be suggested that the nucleation of the reduced silver $\left(\mathrm{Ag}^{0}\right)$ occurred by bioreduction [17,18]. Thus, it is possible that $\mathrm{Ag}^{0}$ is inside the particles, while components of the extracts are on the periphery of the AgNPs. This is because the Zeta potential of AgNPs presented a negative charge in all extract concentrations.

AgNPs prepared by $A$. muricata pulp extract without exposure to artificial light showed the best PDI. These AgNPs were monodispersed, similarly to the AgNPs prepared using extract by $A$. muricata seeds with exposure to artificial light. The contrast to AgNPs prepared by $A$. muricata leaf extract, with or without exposure to artificial light, showed a PDI above 0.5 , which suggests the heterogeneity of the particles formed.

\section{Morphological and surface evaluation by FEG}

AgNPs had a spherical shape, which is in agreement with the results of UV-vis spectroscopy of the AgNPs, where the absorption peaks were between 424 and $444 \mathrm{~nm}$ [19].

AgNPs obtained by the extract of the pulp of $A$. muricata and with exposure to artificial light, presented a larger size, $60 \mathrm{~nm}$, compared to AgNPs obtained by extract of the pulp of $A$. muricata without exposure to artificial light, where the average size was $31 \mathrm{~nm}$. AgNPs obtained by $A$. muricata seed extract, with and without exposure to artificial light, presented similar size. The average size for AgNPs exposed to artificial light were $54 \mathrm{~nm}$ and for AgNPs that were not exposed to artificial light was $47 \mathrm{~nm}$. Similarly, the AgNPs obtained by $A$. muricata leaf extract, with and without exposure to artificial light, showed an average of 54 nm. Agglomerated AgNPs can also be seen (Figure 4). 

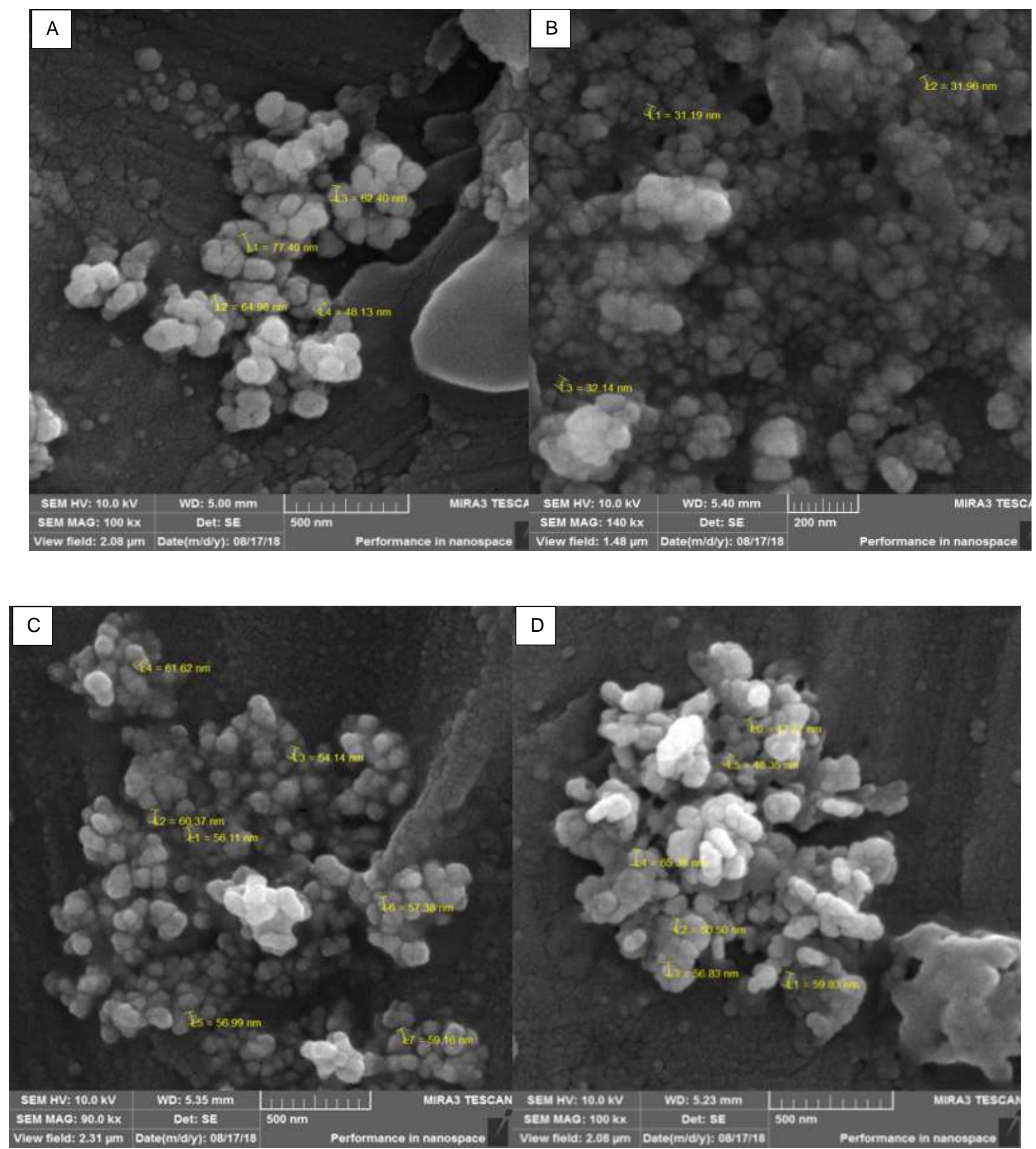


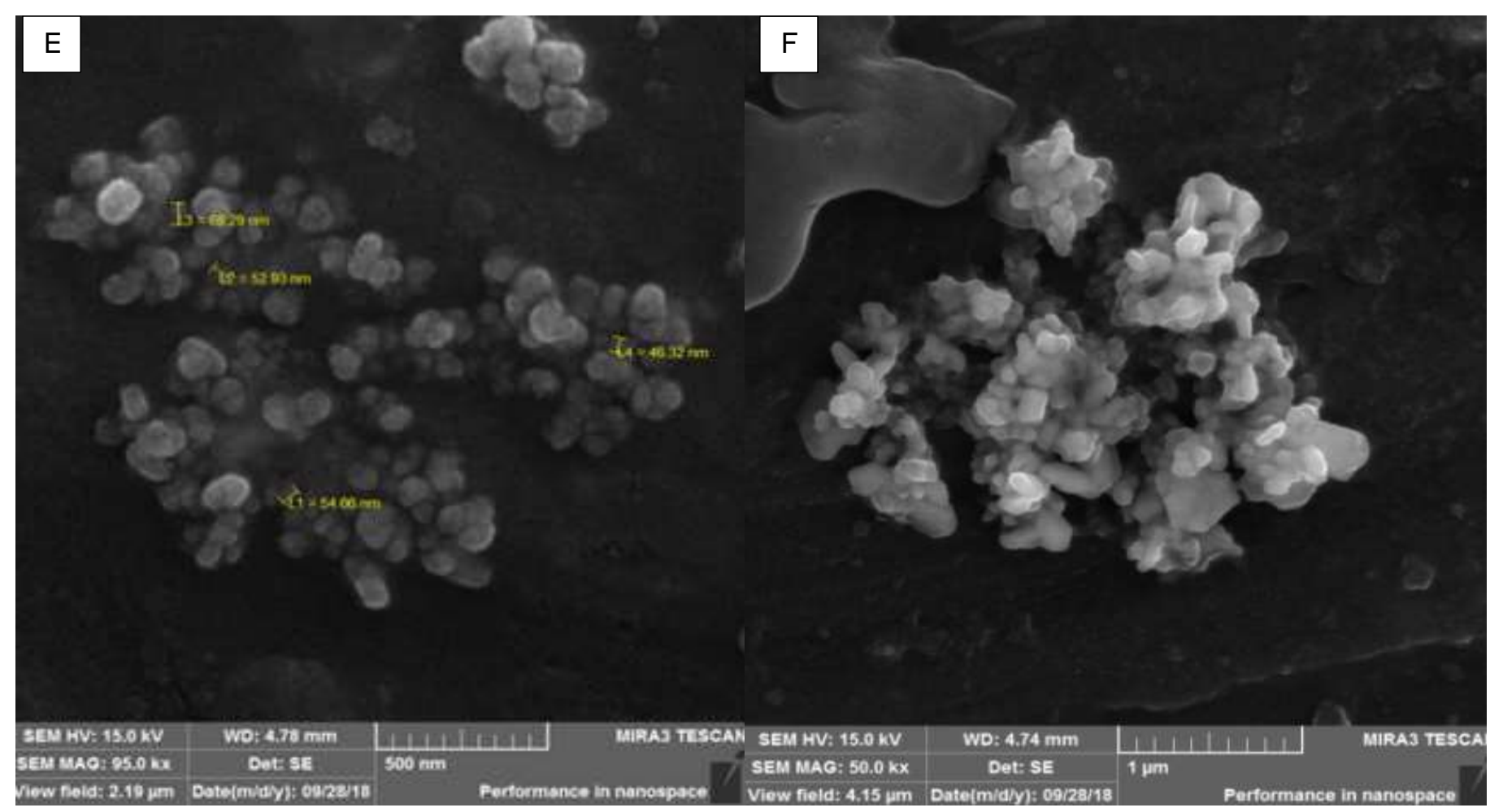

Figure 4. Photomicrographs of AgNPs synthesized from A. muricata pulp extract with exposure to artificial light $(A)$ and without exposure to artificial light (B); AgNPs synthesized from the extract of $A$. muricata seeds with exposure to artificial light (C) and without exposure to artificial light (D); AgNPs synthesized from A. muricata leaves extract with exposure to artificial light (E) and without exposure to artificial light (F).

Haldar and coauthors [20], using Pinus roxburghii pulp extract, obtained AgNPs with morphological characteristics and average size of 20 to $53 \mathrm{~nm}$ similar to those obtained in the present work. Micrographs of the synthesized AgNPs of leaves extract of $A$. muricata show a spherical shape and structure and measured at 20 to $70 \mathrm{~nm}$ [21].

\section{Analysis by fourier-transform infrared spectroscopy (FTIR)}

The FTIR analysis allows characterizing the functional groups involved in the synthesis of AgNPs. The FTIR of the AgNPs (Figure 5) revealed bands at $3457 \mathrm{~cm}^{-1}$, attributed to the $(\mathrm{O}-\mathrm{H})$ stretching frequency of the phenolic group and alcohols, present in flavonoids, which appear in the range $3500 \mathrm{~cm}^{-1} \mathrm{e} 3200 \mathrm{~cm}^{-1}$. A band in $1646 \mathrm{~cm}^{-1}$ referring to the stretching of the functional group $(C=O)$ linked to the aromatic rings of the flavonoids is observed in the 1680 a $1620 \mathrm{~cm}^{-1}$ [22]. 

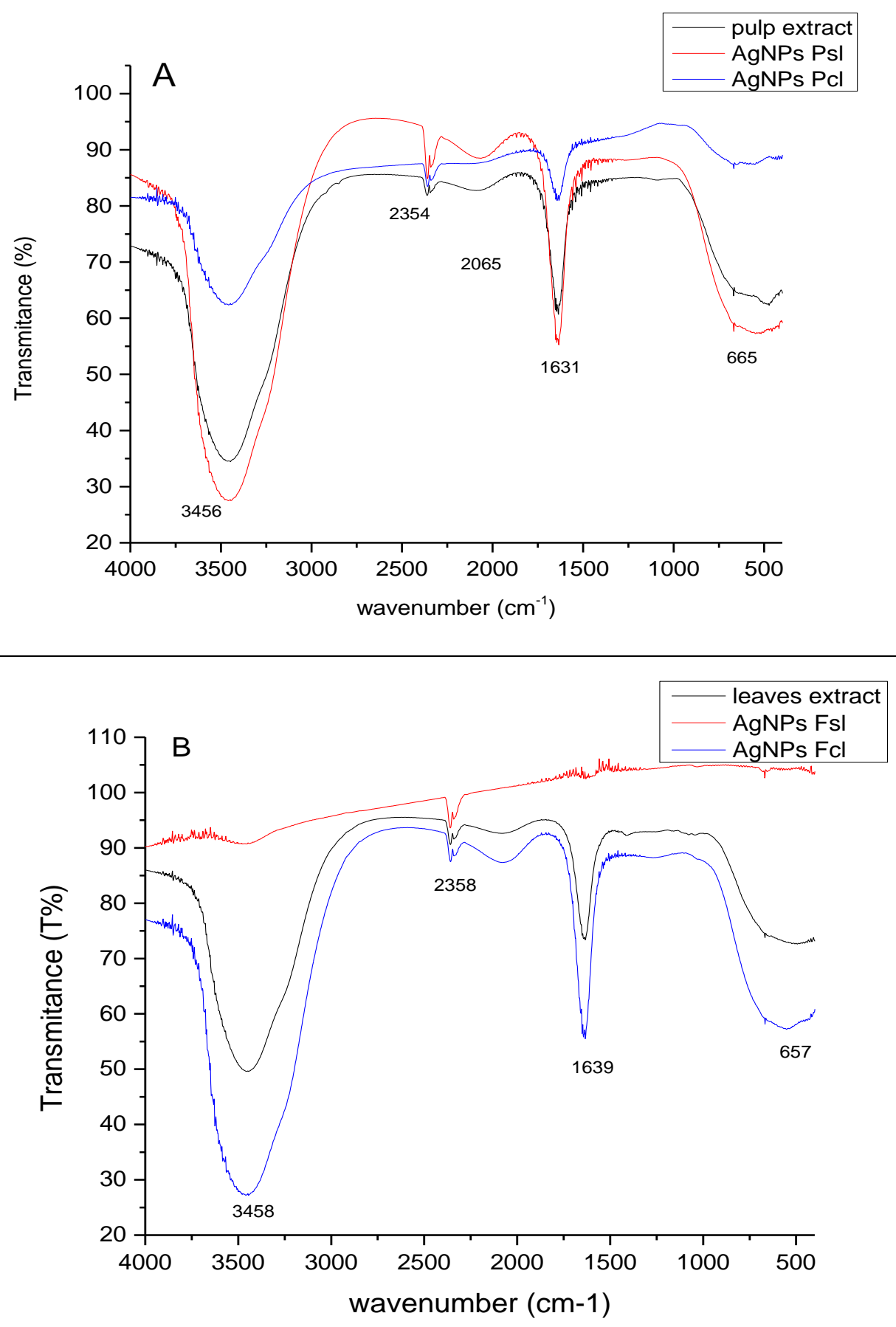


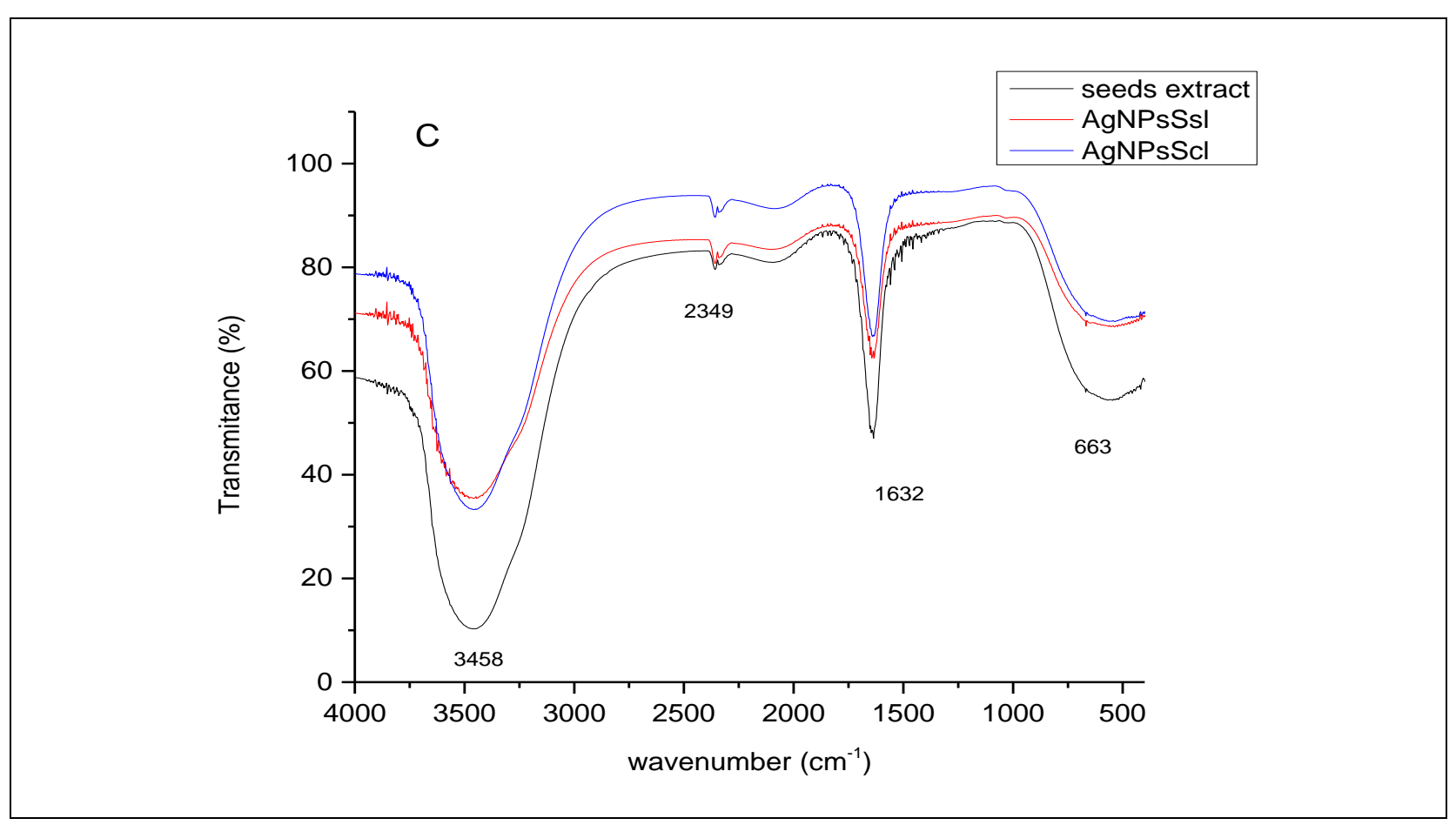

Figure 5. FTIR spectra (A) pulp extract, AgNPs Psl- obtained with A. muricata pulp extract without artificial light; AgNPS $\mathrm{Pcl}$ - obtained with $A$. muricata pulp extract with exposure to artificial light;(B) leaves extract, AgNPs Fsl - obtained with A. muricata leaf extract without exposure to artificial light; AgNPs Fcl- obtained with $A$. muricata leaf extract with exposure to artificial light;(C) seeds extract, AgNPs Ssl- obtained with $A$. muricata seed extract without exposure to artificial light; AgNPs Scl- obtained with A. muricata seed extract with exposure to artificial light.

The results of the present study were similar to those found by Dubey and coauthors [23], who carried out the preparation of silver and gold nanoparticles using the plant extract Tanacetum vulgare. Terpenoids reveal have chains with unsaturation, so the stretching and deformation of the pair $(C=C)$ appear in approximately $1630 \mathrm{~cm}^{-1}$.

These results indicate that the carbonyl group of acetogenins is strongly adsorbed to metals, indicating the interaction with $\mathrm{Ag}$, forming a protective layer around it. This proves the presence of polyphenols, which gives free energy to reduce silver ions for AgNPs [24].

\section{Energy dispersion X-ray spectroscopy (EDS)}

The dispersive energy spectrum revealed the presence of silver as an element of the preparation. All analyzed AgNPs samples show an optical absorption peak at $3 \mathrm{keV}$ due to the plasmon resonance of the surface, proving the presence of the Ag element.

In Figure 6, however, other elements appear, due to the composition of the extract, such as carbon and oxygen. $\mathrm{Al}$ is the element that presents a strong peak at $1.5 \mathrm{keV}$, indicative of the composition of the stub. 


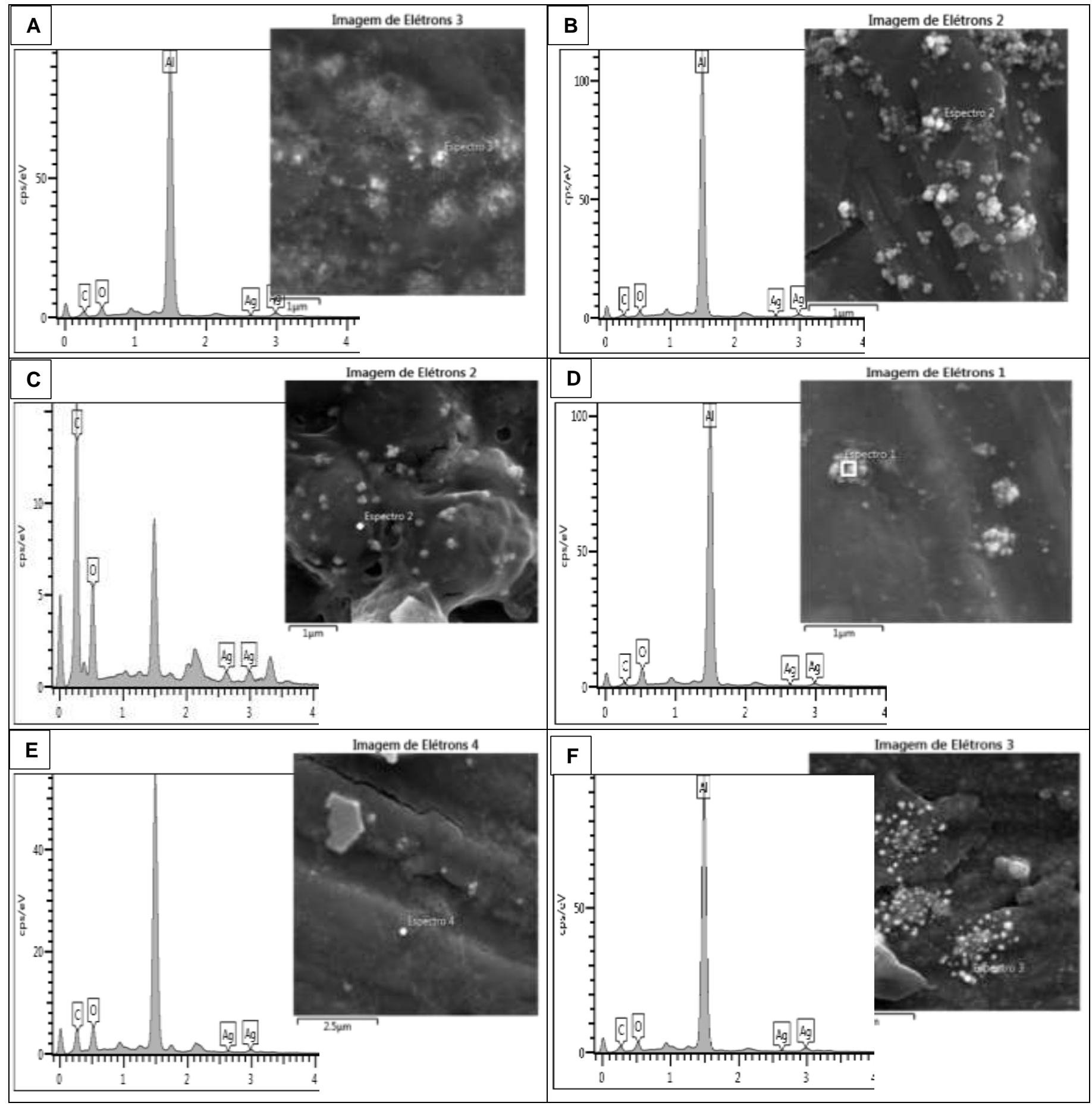

Figure 6. EDS spectra of AgNPs: (A) AgNPs obtained with $A$. muricata pulp extract with exposure to artificial light, (B) AgNPs obtained with $A$. muricata pulp extract without exposure to artificial light; (C) AgNPs obtained with $A$. muricata leaf extract with exposure to artificial light; (D) AgNPs obtained with $A$. muricata leaf extract without exposure to artificial light; (E) AgNPs obtained with $A$. muricata seed extract with exposure to artificial light; (F) AgNPs obtained with $A$. muricata seed extract without exposure to artificial light.

\section{Antimicrobial activity and antifungal of AgNps obtained with pulp, leaf and seeds $\boldsymbol{A}$. muricata extract}

The leaf extract of $A$. muricata did not show bacteriostatic activity against any bacterial strains tested but showed fungistatic action against Candida albicans. The pulp and seed extract of $A$. muricata showed bacteriostatic activity against strains of $S$. aureus, E. faecalis, E. coli, K. pneumoniae, P. mirabilis; however it did not have bacteriostatic activity against $P$. aeruginosa. None of the $A$. muricata extracts show bactericidal activity.

On the other hand, AgNPs produced by pulp, leaves and seeds extract, with and without exposure to artificial light, showed bacteriostatic activity at a concentration of $5.4 \mu \mathrm{g} / \mathrm{mL}$, against the strains of 
Staphylococcus aureus, Enterococcus faecalis, Escherichia coli, Klebsiella pneumoniae, Proteus mirabilis e Pseudomonas aeruginosa and fungistatic action against Candida albicans (Table2).

In assessing bactericidal activity, AgNPs obtained by $A$. muricata pulp extract with exposure to artificial light were effective against $E$. coli, $K$. pneumoniae and P. mirabilis at a concentration of $5.4 \mu \mathrm{g} / \mathrm{mL}$. AgNPs obtained by $A$. muricata leaf extract with exposure to artificial light showed bactericidal activity against $C$. albicans, while AgNPs obtained by $A$. muricata seed extract with exposure to artificial light did not show bactericidal activity Table2).

AgNPs obtained by $A$. muricata pulp extract without exposure to artificial light showed bactericidal activity at a concentration of $5.4 \mu \mathrm{g} / \mathrm{mL}$ against $K$. pneumoniae. The AgNPs obtained by $A$. muricata leaf extract without exposure to artificial light showed bactericidal activity at a concentration of $5.4 \mu \mathrm{g} / \mathrm{mL}$ against $K$. pneumoniae and against $E$. coli. AgNPs of the seed without exposure to light showed bactericidal activity in the concentration of $5.4 \mu \mathrm{g} / \mathrm{mL}$, against $S$. aureus (Table 2).

These results demonstrated greater effectiveness of the AgNPs obtained by the extracts of $A$. muricata against bacteria and fungi, compared to the pure extract.

Table 2. Activity antimicrobial and antifungal: MIC and MBC.

\begin{tabular}{|c|c|c|c|c|c|c|c|c|c|c|c|c|}
\hline \multirow[t]{2}{*}{ Microorganisms } & \multicolumn{2}{|c|}{$\begin{array}{c}\text { AgNPs Pcl } \\
(\mu \mathrm{g} / \mathrm{mL})\end{array}$} & \multicolumn{2}{|c|}{$\begin{array}{c}\text { AgNPs Psl } \\
(\mu \mathrm{g} / \mathrm{mL})\end{array}$} & \multicolumn{2}{|c|}{$\begin{array}{c}\text { AgNPs Fcl } \\
(\mu \mathrm{g} / \mathrm{mL})\end{array}$} & \multicolumn{2}{|c|}{$\begin{array}{c}\text { AgNPs Fsl } \\
(\mu \mathrm{g} / \mathrm{mL})\end{array}$} & \multicolumn{2}{|c|}{$\begin{array}{c}\text { AgNPs Scl } \\
(\mu \mathrm{g} / \mathrm{mL})\end{array}$} & \multicolumn{2}{|c|}{$\begin{array}{l}\text { AgNPs Ssl } \\
(\mu \mathrm{g} / \mathrm{mL})\end{array}$} \\
\hline & $\mathrm{MIC}$ & MBC & $\mathrm{MIC}$ & MBC & MIC & MBC & MIC & MBC & MIC & MBC & MIC & $\mathrm{MBC}$ \\
\hline S.aureus & 5.4 & - & 5.4 & - & 5.4 & - & 5.4 & - & 5.4 & - & 5.4 & 5.4 \\
\hline E.faecalis & 5.4 & - & 5.4 & - & 5.4 & - & 5.4 & - & 5.4 & - & 5.4 & - \\
\hline E.coli & 5.4 & 5.4 & 5.4 & - & 5.4 & - & 5.4 & 5.4 & 5.4 & - & 5.4 & - \\
\hline$P$. aeruginosa & 5.4 & - & 5.4 & - & 5.4 & - & 5.4 & - & 5.4 & - & 5.4 & - \\
\hline P.mirabilis & 5.4 & 5.4 & 5.4 & - & 5.4 & - & 5.4 & - & 5.4 & - & 5.4 & - \\
\hline K. pneumoniae & 5.4 & 5.4 & 5.4 & 5.4 & 5.4 & - & 5.4 & 5.4 & 5.4 & - & 5.4 & - \\
\hline C. albicans & 5.4 & - & 5.4 & - & 5.4 & 5.4 & 5.4 & - & 5.4 & - & 5.4 & - \\
\hline
\end{tabular}

AgNPs - silver nanoparticles; Pcl- $A$. muricata pulp extract and exposure to light; Psl- $A$. muricata pulp extract without exposure to light; $\mathrm{Fcl}$ - $A$. muricata leaf extract and exposure to light; $\mathrm{Fsl}-A$. muricata leaf extract without exposure to light; Scl - A. muricata seed extract with exposure to light; Ssl - A. muricata seed extract without exposure to light. MIC (minimum inhibitory concentration); MBC (minimum bactericidal concentration).

Vieira and coauthors [5] demonstrated antibacterial activity of $A$. muricata leaf extract prepared by ethanol and methanol against $S$. aureus, whereas the aqueous extract showed no activity.

Lima and coauthors [25], using aqueous extract of $A$. muricata had a bactericidal effect against $S$. aureus and $V$. cholerae, however, the ethanolic extracts of this plant did not show antibacterial activity. The bioactivity of water-based $A$. muricata extracts may be related to the chemical structure of the active substances.

\section{Stability study of the produced AgNPs}

The stability assessment (Figure 7) showed that the AgNPs obtained by $A$. muricata pulp extract without exposure to artificial light (Figure 7B) and the AgNPs obtained by $A$. muricata pulp extract by exposure to artificial light (Figure 7A), remained stable, which can be observed by maintaining the absorption peak in the same range as in the UV-vis spectrum, during the analyzed period. This result is indicative that the AgNPs produced by $A$. muricata pulp extract without exposure to artificial light and the AgNPs produced by $A$. muricata pulp extract with exposure to artificial light, maintained the size and homogeneity of the particles.

However, it is observed that the AgNPs produced by A. muricata pulp extract with exposure to artificial light had a reduction in the absorption peak in the two evaluated intervals, which may be due to a reduction in the concentration of nanoparticles present in the sample.

The AgNPs produced by $A$. muricata leaf extract without exposure to artificial light (Figure 7D), maintained the peak of absorption in the same range, in the evaluated periods, however, there is a great reduction in the peak of absorption of the AgNPs produced by extract of leaves of $A$. muricata with exposure to artificial light (Figure 7C), after 90 days and after 1 year. This indicates a reduction in the number of particles in the sample.

It is also possible to see a widening of the peaks in these spectra, which suggests that the distribution of AgNPs produced by $A$. muricata leaf extract without exposure to artificial light, suffered agglomeration, presenting a heterogeneous sample. 
The AgNPs produced by $A$. muricata seed extract without exposure to artificial light (Figure 7F) maintained the absorption peak in UV-vis in the same absorption range, but showed a reduction in peak intensity, indicating a reduction in nanoparticles in the preparation after 90 days of evaluation. After the period of 1 year, it can be observed that there was a shift in the absorption peak from 424 to $452 \mathrm{~nm}$. This phenomenon occurs when there is an increase in the size of the nanoparticles.

It is also possible to evidence a reduction in the intensity of absorption and a widening in the amplitude in the wavelength, which is due to the decrease of the quantity and, also, agglomeration of the nanoparticles. The AgNPs produced with $A$. muricata seed extract with exposure to artificial light did not show a large change in the UV-vis absorption range; however, the reduction in the peak absorption intensity in the two analyzed periods is evident (Figure 7E). 


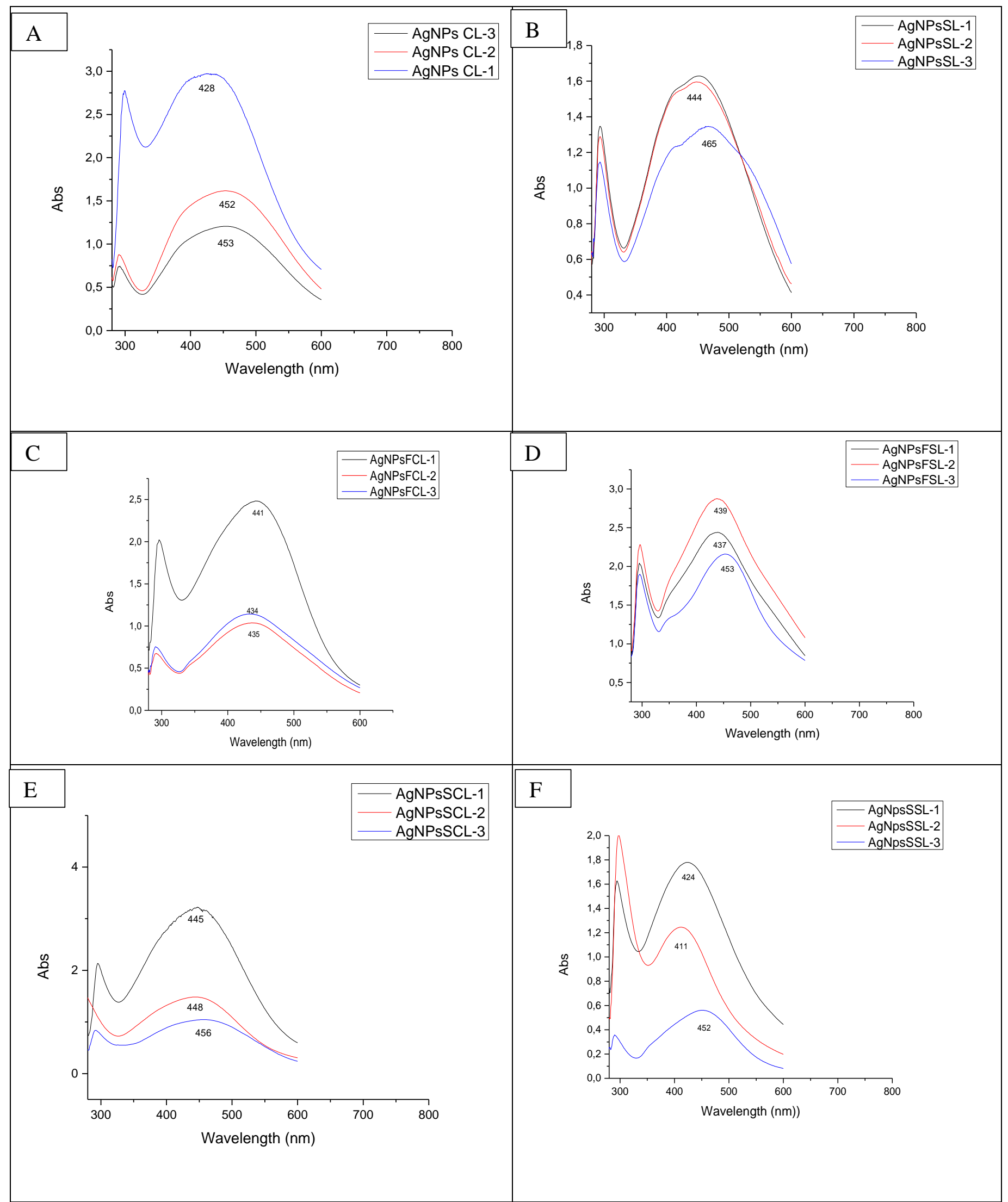

Figura 7. UV-vis spectra of AgNPs obtained from A. muricata pulp extract, with exposure to artificial light (A) and without exposure to artificial light (B). UV-vis spectra of AgNPs obtained from $A$. muricata leaf extract, with exposure to artificial light (C) and without exposure to artificial light (D). UV-vis spectra of AgNPs obtained from $A$. muricata seed extract with exposure to artificial light (E) and without exposure to artificial light (F);1 - day of preparation; 2 - 90 days of refrigeration; 3 - 1 year of refrigeration. 
Similar findings were also observed using Bambou arundinaceae leaf extracts as a reducing agent in the synthesis of silver nanoparticles. The use of extracts provides stability in some preparations [26].

The decrease in the absorption intensity refers to a decrease in the concentration of nanoparticles, which may have suffered degradation during the stability assessment period.

The analysis of UV-vis spectroscopy showed that exposure to artificial light was crucial to trigger this phenomenon, as can be seen in Figures 7 ( $A, C$, and $E)$.

\section{CONCLUSION}

The extracts of the pulp, seeds and leaves of $A$. muricata were efficient for the green synthesis of AgNPs.

The use of artificial light had a positive impact on the synthesis of AgNPs, accelerating the formation process; however, it favored the agglomeration of AgNPs.

AgNPs with more adequate characteristics, size, PDI, zeta potential and stability were obtained with $A$. muricata pulp extract and without exposure to artificial light.

AgNPs showed antimicrobial activity against strains of gram positive and gram negative bacteria and antifungal activity.

Conflicts of Interest: "The authors declare no conflict of interest."

\section{REFERENCES}

1. Jabir NR, Tabrez S, Ashraf GM. Nanotechnology-based approaches in anticancer research. Int. J. Nanomedicine. 2012;(7):4391-4408.

2. Alves GP, Martins F, Santana MHA. Nanotecnologia aplicada ao desenvolvimento de produtos farmacêuticos. Fármacos \& Medicamentos. 2008;(9):44-50.

3. Marambio-Jones EMC, Hoek V. A review of the antibacterial effects of silver nanomaterials and potential implications for human health and the environment. J. Nanopart. Res. 2010;(12):1531-51.

4. Arunachala MDK, Annamalai S, HARI S. One-step green synthesis and characterization of leaf extract-mediated biocompatible silver and gold nanoparticles from Memecylon umbellatum. Int. J. Nanomedicine. 2013;(8):1307-15.

5. Vieira GHF, Mourão JA, Ângelo AM, Costa RA, Vieira RHSF. Antibacterial effect (in vitro) of Moringa oleifera and Annona muricata against Gram positive and Gram negative bacteria. Rev. Inst. Med. Trop. São Paulo. 2010;52(3):129-32.

6. Pileni MP. Fabrication and physical properties of self-organized silver nanocrystals. Pure Appl. Chem. 2000;(72):5365.

7. Agu CK, Okolie PN, Falodun A, Engel-Lutz N. In vitro anticancer assessments of Annona muricata fractions and in vitro antioxidant profile of fractions and isolated acetogenin (15-acetyl guanacone). J. Cancer Res. and Practice. 2018;(5):53-66.

8. Radji M, Kurniati M, Kiranasari A. Comparative antimycobacterial activity of some Indonesian medicinal plants against multi-drug resistant Mycobacterium tuberculosis. J. Appl. Pharm. Sci. 2015; 5(1):19-22.

9. Mohanty S, Hollinshead J, Jones L, Jones PW, Thomas D, Watson AA. Annona muricata (Graviola): toxic or therapeutic. Nat. Prod. Commun.2008;3(1):31-3.

10. Tang, B. et al. Colorful and antibacterial silk fiber from anisotropic silver nanoparticles. I. Ind Eng Chem. Res. 2013;52(12):4556-63.

11. Noguez C. Surface plasmons on metal nanoparticles: the influence of shape and physical environment, J. Phys. Chem. 2007;111:3806-19.

12. Ashraf JM et al. Green synthesis of silver nanoparticles and characterization of their inhibitory effects on AGEs formation using biophysical techniques. Sci. Rep. 2016;(6):204-14.

13. Chauduri GR, Paria S. Core/Shell Nanoparticles, Classes, Properties, Synthesis Mechanisms, Characterization, and Applications. Chem. Rev.. 2012;(112):2373-433

14. Sukirtha R, Priyankaa MK, Antonya JJ, Kamalakkannana S, Thangamb R, Gunasekaranb P, Krishnana M, Achiramana S. Cytotoxic effect of Green synthesized silver nanoparticles using Melia azedarach against in vitro HeLa cell lines and lymphoma mice model. Process Biochem. 2012;(47):273-9.

15. Cardoso V S. et al. Collagen-based silver nanoparticles for biological applications: synthesis and characterization. J. Nanobiotechnology. 2014;12(1):36.

16. Neves AR. et al. Novel resveratrol nanodelivery systems based on lipid nanoparticles to enhance its oral bioavailabity. Int. J. Nanomedicine. 2013;(8):177-87.

17. Akhtar BS et al. Biogenic synthesis of metallic nanoparticles by plant extracts. ACS Sustain. Chem. Eng. 2013;(1):591-602. 
18. Mittal A K et al. Synthesis of metallic nanoparticles using plant extracts. Biotechnol. Adv. 2013;31(2):346-56.

19. Solomon S, Bahadory M, Jeyarajasingan A, Rutkowsky S, Boritz C. Synthesis and study of silver nanoparticles. EUA: J. Chem. Educ. 2007; 84(2):322.

20. Haldar KM, Haldar B, Chandra, G. Fabrication, characterization and mosquito larvicidal bioassay of silver nanoparticles synthesized Parasitol Res from aqueous fruit extract of putranjiva. Drypetes roxburghii (Wall.). Parasitol. Res. 2013;(112):1451-9.

21. Santosh SB, Yuvarajan R, Natarajan D. Annona muricata leaf extract-mediated silver nanoparticles synthesis and its larvicidal potential against dengue, malaria and filariasis vector. Parasitol. Res. 2015;(114):3087-96.

22. Pretsch E, Buhlmann P, Affolter C. Structure Determination of Organic Compounds. 4nd ed. Springer; 2009. 491 p.

23. Dubey APS, Lahtinenb M, Sillanpa AM. Tansy fruit mediated greener synthesis of silver and gold nanoparticles. Process Biochem. 2010; (45):1065-71.

24. Shrivastava S, Dash D. Label-free colorimetric estimation of proteins using nanoparticles of silver, Nano-Micro Lett. 2010; (2):164-8.

25. Lima MRF, Ximenes ECPA, Luna JS, Santana,AEG. The antibiotic activity of some Brazilian medicinal plants. Rev. Bras. Farmacogn. 2006;(16):300-6.

26. Kalaiarasi K, Prasannaraj G, Sahi VS, Venkatachalam P. Phytofabrication of biomolecules coated metallic silver nanoparticles using leaf extracts of in vitro raised bamboo species and its anticancer activity against human PC3 cell lines. Turk. J. Biol. 2015;(39):223-32.

2021 by the authors. Submitted for possible open access publication under the terms and conditions of the Creative Commons Attribution (CC BY NC) license (https://creativecommons.org/licenses/by-nc/4.0/). 